consummation of his marriage with a goddess was an essential part of the annual ritual. This ceremony was well known from other sources, but Tell Asmar has afforded on a seal the only known representation of the divine nuptials in early Mesopotamia.

Among a hoard of copper objects enclosed in a pot was a bronze open-work dagger-handle in which was wedged a fragment of the original blade. This has been examined by Dr. C. H. Desch, who pronounces it to be iron of telluric origin. As it belongs to the 28th century B.C., it is by many hundreds of years the earliest example known. The same applies to a fragment of clear glass which has been examined by Mr. Horace C. Beck, who points out how surprising it is to find in Mesopotamia clear glass dating from 2700 B.c., since in Egypt, although opaque glass was known in the second millennium B.c., clear glass was not introduced before Roman times.

It has been possible to touch only on the more striking points in Dr. Frankfort's report, while the excavations at Khafaje and Khorsabad must be passed over, notwithstanding their interest and importance. The excavations of the Oriental Institute closed for the season in 1933 at a point which promised much in the following season. This expectation was not disappointed and the further reports of the director are awaited with interest.

\title{
Three-Colour, One-Exposure Camera
}

$\mathrm{T}$ HE customary method of making a set of colourseparation negatives for colour photography is by successive exposures on separate plates through the appropriate colour filters. Usually three negatives are required. This method fails for snapshot exposures of moving objects. For many years inventors have attempted to devise three-colour cameras operating with a single exposure during which all three images are simultaneously recorded. Several of the optical devices which have been used to achieve this end were briefly described by Dr. D. A. Spencer in 1933 (Photographic J., 74, 103; 1934) and a further method was described in 1934 (ibid., 74,244 ; 1934) by the late Mr. W. T. P. Cunningham.

One of the less difficult methods depends on the use of two inclined, semi-reflecting, plane mirrors. Light from the camera lens strikes the first mirror and a portion of it is deflected to form an image on one of the photographic plates placed behind its suitable colour filter; the remainder of the light goes on and meets the second mirror, which deflects a portion on to another plate, and the remainder goes on to the back of the camera where the third filter and plate are situated. One objection to this method is that reflection takes place at both surfaces of each mirror and, if the mirrors are thick, double images may be formed. This has led to the use of thin pellicle mirrors which are said to have been suggested by Geisler so long ago as 1910 (see Spencer, loc. cit) and have recently been made as commercial articles by Mr. H. O. Klein. It is said that other ways of avoiding double images with this general arrangement of semi-reflecting mirrors are also available.

The method has therefore led to considerable practical success and at present there are available two cameras which make use of it. These were both shown at the recent British Industries Fair. One is the Taylor-Hobson three-colour camera (Vivex system) and the other is the Klein tri-colour camera invented by Adrian B. Klein and manufactured by Messrs. Bellingham and Stanley, Itd. These cameras are said to work successfully to give exposures ranging from $1 / 25$ sec. to $1 / 10 \mathrm{sec}$. in winter sunshine. In quiries about these cameras should be addressed, in relation to the first to Messrs. Colour Photographs (British and Foreign), Ltd., Victoria Road, Willesden, N.W.I0, and in relation to the second to Messrs. Farquhar and Moloney, 15-16 Newman Street, London, W.1, or to Messrs. Bellingham and Stanley, Ltd., 71 Hornsey Rise, London, N.19.

\section{A Japanese Scientific Expedition to Manchoukuo*}

\begin{abstract}
7 HE Japanese have lost no time in examining the resources of the new 'independent' kingdom of Manchoukuo, and in October and November of 1934 were published in Tokyo the early sections of a report upon the first Japanese scientific expedition to the country, which carried out exploration work with the aid of motor transport and some aeroplane reconnaissance during the period June to October 1933. Under the leadership of the geologist, Prof. Shigeyasu Tokunaga, of Waseda University, thirteen scientific workers representing geography, botany, zoology and anthropology were dispatched from Japan, largely through the influence of Viscount Toki, Vice-Parliamentary Secretary of the War Office. Never before has a scientific expedition been dispatched abroad from Japan on so big a scale.

- Report of the First Scientiflc Expedition to Manchoukuo under the Leadership of Shigeyasu Tokunaga, June-October 1933. Section 1: Natural Science Research of the First Scientific Expedition to Manchoukuo. By Shigeyasu Tokunaga. Pp. iii $+76+69$ plates Section 4, Part 1: Plantæ Novæ Jeholenses, I. By Takenoshin Naka and Masae Kitagawa. Pp. iv $+71+20$ plates. Section 5, Part 1 The Fresh Water Fishes of Jehol. By Tamezo Mori. Pp. i $+61+21$ plates. (Tokyo : Waseda University, 1934.)
\end{abstract}

The reports now published are in Japanese with a very full transcript in English, which manages to express some of the enthusiasm with which the expedition has undertaken its task, regarded as important both on patriotic and scientific grounds. Before leaving Tokyo on July 22 the members of the expedition assembled in Tokyo in front of the 'Nijiu Bashi' (bridges at the entrance of the Palace) and worshipped at the entrance of the Palace; by July 30 they were in Hsin-king, the capital of Manchoukuo, and there they met again on October 12 "amidst the tear-prompting, enthusiastic welcome of the Government officials as well as plain people". On October 11 in the presence of Viscount Toki "the expedition drank to the happy completion of the scientific investigations at the risk of lives". During the intervening seventy days, some 5,000 kilometres had been covered in automobiles over trackless country; "the bottoms of the rivers are rather shallow [elsewhere described as "abdomendeep"], yet the quagmire-bed so deep. The treacherous rivers!" So far as possible they drove 
along the dry beds of rivers, but frequent storms, which in Jehol turned scorching summer to bitter cold, often delayed or prevented a projected tour. "A proverb goes 'a precipice in front, a wolf behind'; when our march was impeded, we could not safely stay where we were because of there being a danger of bandits' assault". The expedition's work was done undor escort of thirty soldiers and occasionally under additional protection from garrisons.

Dirty and scarce drinking water, and "horribly poisonous insects", with the concomitant troubles of dysentery, trachoma, etc., were probably greater difficulties than the bandits, who only fired upon a camp on one occasion. An endemic epidemic goitre was found to be widespread in south-western Jehol.

The preliminary scientific results are summarised by the head of each section in the first general report (October 1934). A brief stratigraphical summary reports abundant fossil Lycoptera and many fossil insect larvæ (Ephemeropsis) in lower Cretaceous rocks. In loess strata of Middle Pleistocene age, remains of Ovis and Elephas included bone pieces apparently engraved by ancient man. Jehol was a nomad zone originally occupied by Mongolians ; during the Shin dynasty, these Mongolians had declined in prosperity and the Hans (Chinese in the Han dynasty) emigrated there. In the northern district of Manchoukuo the Mongolians still predominate, and throughout the country three systems of farming can be traced, the North Chinese, Manchurian and Mongolian. The animals found still recall the forests, which have been ruthlessly despoiled since the Hans. The November report (Section 4, Part 1) figures and describes eight species of new woody plants (by Dr. T. Nakai) and twenty-nine new herbaceous plants (by Dr. T. Nakai and M. Kitagawa).

Section 5, part 1 , consists of an account of the freshwater fishes of the province of Jehol. This province-a highland area occupying the southwestern part of Manchoukuo and contiguous with the north-eastern border of the Chinese province of Hopei (Chili) - is irrigated by the upper reaches of several rivers in the waters of which and those of associated lakes and ponds $\mathbf{7 8 3}$ fishes were collected. These comprised $\mathbf{3 3}$ species and one sub-species representative of the two families Cyprinidæ and Ophicephalidæ. The detailed taxonomic descriptions are accompanied by twenty-one beautifully produced plates in which all the species are carefully figured, some of them in colour.

\section{Lubricating Value of Mineral Oils}

$\mathrm{I}^{\mathrm{N}}$ 1929 , under the auspices of the Department of Scientific and Industrial Research, a paper (Lubrication Research, Technical Paper No. 1) by the late Sir William Hardy and M. E. Nottage on the analysis of commercial lubricating oils by physical methods was prepared. It was considered, however, inadvisable to draw conclusions from the results of experiments reported therein, since only two oils, and those of unknown origin, had been employed. A further paper by Miss Nottage recently published under similar conditions (Lubrication Research, Technical Paper No. 2. London: H.M. Stationery Office. $9 d$. net) entitled "A Study of the Boundary Lubricating Value of Mineral Oils of Different Origin" is intended in certain respects to supplement the original one.

When the film of lubricating oil separating two smooth bearing surfaces is so thin that no part of it is beyond the range of cohesive forces of attraction transmittable from these surfaces, boundary conditions are said to prevail. Interposition between the two surfaces of a film of oil may, to some extent, neutralise these conditions or, in other words, boundary lubrication may be employed. In these circumstances two important factors must be taken into consideration : the effect of the surface on the oil, honce the nature of the bearing surface, since chemical activity occurring at an interface differs matorially from that occurring in bulk; and chemical properties of the lubricant, the function of which of neutralising the cohesive forces of attraction is effected by the formation of adsorptive layers on the bearing surfaces.

Inasmuch as mineral lubricating oils consist of inactive, non-polar constituents and surface-active polar constituents, from which the greater part of the adsorptive layer is formed, the properties of the film may differ considerably from properties of the oil in bulk. Important factors determining frictionreducing properties of the adsorptive layer are the chemical nature of the constituents and their degree of dispersion. This, in turn, may be varied by changes of temperature, the presence of other substances which play no part in reducing friction, or the solution of oil in certain volatile solvents.

Having regard to the important part played by wax in mineral oils, concurrent investigations were made to obtain some indication of its rôle in a lubricant under boundary conditions. It is shown that, in spite of the general view that wax is detrimental to a lubricant, it does, in certain cases, enhance the lubricating value of the oil at the boundary layer.

\section{University and Educational Intelligence}

Cambridge.-At St. John's College a research studentship and research exhibitions are offered for competition in July 1935. One Strathcona research studentship of the annual value of $£ 150$ is offered for competition among research students who are graduates of any university other than Cambridge. Two Strathcona exhibitions of the annual value of $£ 40$ are also offered for competition under the same conditions as the studentship.

Grants from the Worts Fund have been made as follows :- $£ 75$ to D. B. Keith, A. B. Whatman, and J. W. Wright towards the expenses of an expedition to survey the north coast of North-East Land (Spitsbergen); $£ 120$ to P. T. Cotton, D. W. Ewer and L. E. R. Picken towards the expenses of an expedition to investigate the freshwater ecology of the south west Balkans ; $£ 50$ to T. T. Paterson towards the expenses of an expedition to the North-West Frontier of India for the purpose of studying quaternary deposits ; $£ 2610 s$. to J. R. B. Stewart for archæological investigations in Asia Minor ; $£ 25$ to Dr. T. C. Phemister towards the expenses of a geological and petrological survey of the Coast Range batholith of British Columbia; $£ 25$ to T. G. Tutin for a visit to the Mediterranean coast of Spain to study the destruction of the eel-grass, Zostera marina; $£ 25$ to K. H. Chapman for an expedition to Morocco to study the Moroccan locust, Dociostaurus morocannus.

J. H. Lockhead, of Christ's College, has been nominated to use the University's table at the Zoological Station at Naples. 